\title{
Composição química dos grãos de milho em resposta à adubação mineral e inoculação com rizobactérias ${ }^{1}$
}

\author{
Mariana Alves de Oliveira ${ }^{2}$, Claudemir Zucareli ${ }^{3}$,Leandro Teodoski Spolaor ${ }^{4}$, Allan Ricardo Domingues ${ }^{4}$, \\ André Sampaio Ferreira ${ }^{4}$
}

\section{RESUMO}

Para o aumento da produtividade agrícola no País, são necessários estudos para melhor aproveitamento da adubação mineral, a fim de uma produção de grãos com melhor qualidade nutricional. Este trabalho teve como objetivo avaliar o teor e o acúmulo de proteína, de cinzas e de nutrientes em grãos de milho provenientes de plantas submetidas à inoculação com Pseudomonas fluorescens e cultivadas em diferentes níveis de adubação NPK no solo. Foram testados seis tratamentos, em delineamento experimental de blocos casualizados, no esquema fatorial $3 \times 2$, sendo três níveis de adubação química com NPK $\left(0,125\right.$ e $\left.250 \mathrm{~kg} \mathrm{ha}^{-1}\right)$ e dois níveis de inoculante à base de $P$. fluorescens (com e sem), com quatro repetições, sendo instalado em Latossolo Vermelho eutroférrico, utilizando o cultivar de milho híbrido $30 \mathrm{~F} 35$. Determinaram-se os teores e acúmulo de N, P, K, Ca, Mg, Zn, Cu, Fe, Mn, proteína e cinzas dos grãos. Os dados foram submetidos à análise de variância e as médias, comparadas pelo teste de Tukey ( $\mathrm{p}<0,05)$. A aplicação de $P$. fluorescens via inoculação incrementou os teores de $\mathrm{P}$ e $\mathrm{K}$ dos grãos de milho, independentemente dos níveis de adubação. Os teores dos nutrientes, de proteína e de cinzas dos grãos de milho não foram influenciados pelos níveis de adubação mineral, com exceção do $\mathrm{Cu}$, que aumentou com a elevação dos níveis de adubação.

Palavras-chave: Zea mays, Pseudomonas fluorescens, macronutrientes, micronutrientes, qualidade nutricional.

\section{ABSTRACT}

\section{Chemical composition of corn grains in response to mineral fertilization and inoculation with rhizobacteria}

To increase agricultural productivity in the country, studies are needed to improve the utilization of mineral fertilizers in order to produce grains with improved nutritional quality. The study aimed to evaluate the content and accumulation of protein, ash and nutrients in corn grains from plants inoculated with Pseudomonas fluorescens and grown under different levels of NPK fertilizer in the soil. We tested six treatments in a randomized complete block design in a factorial $3 \times 2$, three levels of chemical fertilizer NPK $\left(0,125\right.$ and $\left.250 \mathrm{~kg} \mathrm{ha}^{-1}\right)$ and two levels of inoculation using $P$. fluorecens (with and without), with four replicates, in a Oxisol, using the maize hybrid 30F35. The content and accumulation of $\mathrm{N}, \mathrm{P}, \mathrm{K}, \mathrm{Ca}, \mathrm{Mg}, \mathrm{Zn}, \mathrm{Cu}, \mathrm{Fe}, \mathrm{Mn}$, protein and ash content of the grains were evaluated. The data were submitted to Anova and means compared by the Tukey test $\mathrm{p}<0.05$. The application of Pseudomonas fluorescens via inoculation increased the $\mathrm{P}$ and $\mathrm{K}$ of corn, regardless of fertilization levels. The contents of nutrient, protein and ash of corn were not influenced by the levels of mineral fertilization, except for $\mathrm{Cu}$ which increased with increasing levels of fertilization.

Key words: Zea mays, Pseudomonas fluorescens, macronutrients, micronutrients, nutritional quality.

\footnotetext{
Recebido para publicação em 04/03/2011 e aprovado em 11/09/2012.

${ }^{1}$ Parte da dissertação de mestrado da primeira autora, apresentada à Universidade Estadual de Londrina, para obtenção do título de Mestre em Agronomia.

${ }^{2}$ Engenheira-Agrônoma. Pós-Graduanda do Departamento de Agronomia, Universidade Estadual de Londrina, Rodovia Celso Garcia Cid, PR 445, Km 380, Caixa Postal 6001, 86051-980, Londrina, Paraná, Brasil. agro-star@ hotmail.com (autora correspondente).

${ }^{3}$ Engenheiro-Agrônomo, Doutor. Departamento de Agronomia, Universidade Estadual de Londrina, Rodovia Celso Garcia Cid, PR 445, Km 380, Caixa Postal 6001, 86051-980, Londrina, Paraná, Brasil. claudemircca@uel.br

${ }^{4}$ Graduando em Agronomia. Universidade Estadual de Londrina, Rodovia Celso Garcia Cid, PR 445, Km 380, Caixa Postal 6001, 86051-980, Londrina, Paraná, Brasil. leandrotspolaor@hotmail.com; allandomingez@hotmail.com; asampaio_5@hotmail.com
} 


\section{INTRODUÇÃO}

O milho é uma das culturas mais exigentes em fertilizantes para expressar seu potencial produtivo, especialmente os nitrogenados, os potássicos e os fosfatados. A adubação nitrogenada influencia não só a produtividade, mas também a qualidade do produto em consequência da alteração no teor de proteína nos grãos de milho (Zhang et al., 1994).

Além de favorecer a produção de grãos, estudos confirmam a influência da adubação com NPK na composição química de grãos quanto ao teor protéico e composição mineral em milho (Ferreira et al., 2001; Carmo et al., 2003; Marsaro Junior et al., 2007) e em milheto (Sobrinho et al., 2009). Entretanto, há menor número de informações quanto aos efeitos da variação nutricional na composição química dos grãos e maior número de relatos quanto aos efeitos de fatores genéticos e ambientais na qualidade do grão de milho, principalmente em relação aos componentes proteína e óleo (Oliveira et al., 2004; Mittelmann et al. 2006; Bueno et al. 2009). No entanto, o acúmulo diferencial de nutrientes no milho varia de acordo com o estádio de maturação, nível e disponibilidade dos nutrientes no solo, do clima, do cultivar e do sistema de cultivo (Vasconcelos et al., 1998; Andreotti et al., 2000; Coelho et al., 2002). Desse modo, a disponibilidade de nutrientes no solo pode influenciar a composição química dos grãos de forma que possa melhorar a sua qualidade nutricional, afetando desde o vigor das sementes até o potencial de armazenamento de grãos.

Com a necessidade do aumento na produtividade agrícola no País, ou até mesmo para manutenção daquelas já alcançadas, torna-se primordial o avanço científico nos estudos objetivando melhor aproveitamento da adubação mineral para uma produção de grãos com melhor qualidade nutricional; ou seja, para aumento nos teores e acúmulo de nutrientes e proteína, uma vez que a maior parte dos grãos é destinada às alimentações animal e humana.

Para aumentar a eficiência na utilização de fertilizantes nos sistemas agrícolas, contribuindo para a maior sustentabilidade da agricultura, aumentou-se o interesse pela manipulação de rizobactérias promotoras do crescimento de planta (RPCPs), as quais fazem parte da população residente das plantas como epifíticas ou endofíticas, não são fitopatogênicas e promovem crescimento das plantas associadas numa relação não simbiótica (Sottero $e t$ al., 2006).

As rizobactérias que se associam a vegetais possuem a capacidade de colonizar as raízes e outros tecidos internos da planta, sendo consideradas promotoras de crescimento vegetal por produzirem hormônios de crescimento. Quanto à produção de hormônios, já se sabe que as rizobactérias são capazes de sintetizar substâncias como as giberelinas e ácido indolacético (AIA) in vitro e na rizosfera de plantas, como é o caso de Pseudomonas spp. em raiz de milho (Pan et al., 1999).

Além de promoverem o crescimento vegetal, as rizobactérias provocam aumento na disponibilidade de nutrientes para as plantas, pela solubilização de fosfato inorgânico (Zaidi \& Khan, 2006; Afzal \& Bano, 2008), de nitrogênio e de outros elementos (Sheng \& He, 2006; Glick et al., 2007) e, por favorecer o crescimento do sistema radicular, aumento do número de pêlos nas raízes, consequentemente aumento da área superficial do sistema radicular (Mantelin \& Touraine, 2004).

Dessa forma, as práticas de manejo de adubação, juntamente com a inoculação de Pseudomonas fluorescens na semente, podem alterar tanto o acúmulo quanto a remobilização de nutrientes das diferentes partes da planta para os grãos, alterando assim a sua composição química e nutricional. Realizou-se este trabalho com o objetivo de avaliar o teor e o acúmulo de proteínas, de cinzas e de nutrientes em grãos de milho provenientes de plantas submetidas à inoculação com Pseudomonas fluorescens e cultivadas em diferentes níveis de adubação NPK no solo.

\section{MATERIAL E MÉTODOS}

Este trabalho foi realizado na Fazenda Escola e no Laboratório de Solos da Universidade Estadual de Londrina (FAZESC-UEL), localizada no município de Londrina-PR, que se encontra a $23^{\circ} 22^{\prime}$ Sul, $51^{\circ} 22^{\prime}$ 'Oeste, com altitude de $580 \mathrm{~m}$.

O clima característico da região, de acordo com a classificação de Köppen, é do tipo CFA; ou seja, clima subtropical úmido mesotérmico, com verões quentes e geadas pouco frequentes. As chuvas tendem a se concentrar nos meses de verão, sem estação seca definida, com precipitação média anual de $1.614 \mathrm{~mm}$ e insolação média anual de 7,05 horas por dia. A temperatura média anual é de $20,2^{\circ} \mathrm{C}$, a média das temperaturas máximas é de $27,0^{\circ} \mathrm{C}$ e a média das temperaturas mínimas, de $14,8^{\circ} \mathrm{C}$. A umidade relativa do ar média é de $75 \%$ (Iapar, 2008). As temperaturas máximas e mínimas diárias e a precipitação pluvial diária durante o período de condução do experimento, obtidas na estação metereológica do Instituto Agronômico do Paraná, localizado em Londrina-PR, estão apresentadas na Figura 1.

A instalação do experimento foi realizada no dia 18 de fevereiro de 2009, seguindo as recomendações de época do Instituto Agronômico do Paraná (Iapar, 2009), que preconizava a instalação da cultura de milho safrinha para a região de Londrina-PR até a data-limite de 20 de março. Foi utilizada a cultivar de milho híbrido 30F35 Pioneer, que 
apresenta ciclo precoce, alto potencial produtivo e elevada capacidade de adaptação para a safrinha (Pioneer Sementes, 2009).

O experimento foi instalado em solo classificado como Latossolo Vermelho eutroférrico (Embrapa, 1999). Previamente à instalação do experimento foram coletadas amostras de solo da área experimental na profundidade de 0-10 e 10-20 cm para análise química, de acordo com a metodologia de Raij \& Quaggio (1983). O solo foi preparado quando apresentava condições adequadas de umidade, realizando-se aração e gradagem.

Foram avaliados seis tratamentos, utilizando-se o delineamento experimental de blocos casualizados, em esquema fatorial $3 \times 2$, correspondente a três níveis de adubação NPK, sendo uma testemunha sem adubação e as quantidades do fertilizante 08-28-16 de 125 e $250 \mathrm{~kg} \mathrm{ha}^{-1}$, combinados a dois níveis de inoculante (com e sem), com quatro repetições. As adubações de NPK foram calculadas com base nos resultados da análise química do solo (Tabela 1) e nas recomendações para a região (Embrapa, 2009), sendo a dose de $250 \mathrm{~kg} \mathrm{ha}^{-1}$ correspondente a $100 \%$ da recomendação.
As sementes foram tratadas momentos antes da semeadura, com o inoculante à base de Pseudomonas fluorescens, Rizofos ${ }^{\circledR}$, contendo a Estirpe 1008 (coleção de culturas da Rizobacter Argentina S.A.), sendo utilizados $140 \mathrm{~mL} \mathrm{ha}^{-1}$, correspondente a $100 \mathrm{~mL}$ de Rizofos ${ }^{\circledR} \mathrm{e}$ $40 \mathrm{~mL}$ de Premax- $\mathrm{R}^{\circledR}$ (protetor bacteriano que melhora a sobrevivência das bactérias após a inoculação). A inoculação consistiu em colocar as sementes e o produto em saco plástico, com posterior agitação para distribuição homogênea do inoculante sobre as sementes.

As parcelas foram constituídas de quatro linhas de cinco metros de comprimento, com espaçamento entre linhas de 0,9 m. Foram consideradas como parcela útil as duas linhas centrais, desprezando-se $0,5 \mathrm{~m}$ de suas extremidades. A semeadura foi realizada manualmente no sistema convencional de cultivo. Para atingir a densidade de aproximadamente 55.000 plantas $\mathrm{ha}^{-1}$, realizou-se o desbaste na fase de desenvolvimento $\mathrm{V}_{3}$, utilizando-se a escala fenológica da cultura proposta por Ritchie et al. (1986).

Durante o desenvolvimento da cultura a área experimental foi monitorada com relação às pragas, doenças e plantas daninhas. Houve necessidade de controle de va-

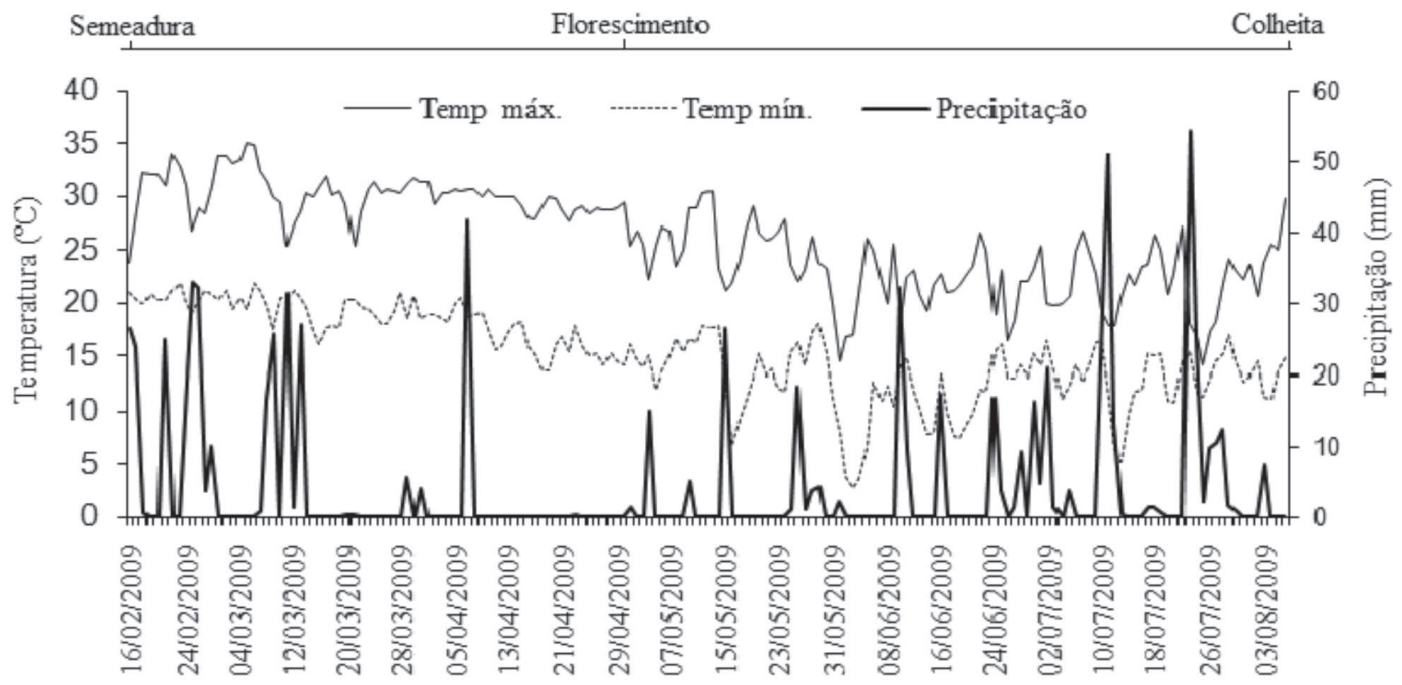

Figura 1. Dados diários de temperaturas máximas e míninas e de precipitação pluvial durante o período de condução do experimento em Londrina-PR no ano de 2009.

Tabela 1. Caracterização química do solo da área experimental na profundidade de 0-10 e 10-20 cm

\begin{tabular}{|c|c|c|c|c|c|c|c|c|c|}
\hline \multirow{2}{*}{$\frac{\text { Prof. }}{(\mathrm{cm})}$} & \multicolumn{2}{|c|}{ pH } & $\mathbf{H}+\mathbf{A l}$ & $\mathrm{Ca}^{2+}$ & $\mathbf{M g}^{2+}$ & $\mathbf{K}^{+}$ & CTC & $\mathbf{V}$ & $\mathbf{P}$ \\
\hline & $\mathrm{CaCl}_{2}$ & $\mathrm{H}_{2} \mathrm{O}$ & \multicolumn{5}{|c|}{$\mathrm{cmol}_{\mathrm{c}} \mathrm{dm}^{-3}$} & $\%$ & $\mathrm{mg} \mathrm{dm}^{-3}$ \\
\hline $0-10$ & 5,3 & 6,0 & 4,2 & 5,7 & 1,5 & 0,9 & 12,3 & 66,27 & 10,51 \\
\hline $10-20$ & 5,1 & 5,7 & 4,9 & 4,6 & 1,2 & 0,4 & 11,1 & 55,53 & 6,46 \\
\hline Prof. & \multicolumn{2}{|c|}{ Mn } & \multicolumn{2}{|c|}{$\mathrm{Fe}$} & \multicolumn{2}{|c|}{$\mathrm{Cu}$} & $\mathbf{Z n}$ & \multicolumn{2}{|r|}{ B } \\
\hline$(\mathrm{cm})$ & \multicolumn{9}{|c|}{$\mathrm{mg} \mathrm{dm^{-3 }}$} \\
\hline $0-10$ & \multicolumn{2}{|c|}{224,2} & \multicolumn{2}{|c|}{64,99} & \multicolumn{2}{|c|}{17,40} & 12,26 & \multicolumn{2}{|r|}{0,66} \\
\hline $10-20$ & \multicolumn{2}{|c|}{214,5} & \multicolumn{2}{|c|}{73,69} & \multicolumn{2}{|c|}{17,22} & 2,92 & \multicolumn{2}{|r|}{0,84} \\
\hline
\end{tabular}

* Extratores: Ca, Mg, Al: KCl; P, K: Mehlich-I; Mn, Fe, Cu, Zn: Mehlich-I; B: HCl 0,05 N. 
quinha (Diabrotica speciosa), devido à desfolha causada pelo inseto adulto no estádio $\mathrm{V}_{3}$ da cultura. Utilizou-se Teflubenzuron na dosagem de $100 \mathrm{~mL} \mathrm{ha}^{-1}$. A eliminação de plantas daninhas foi realizada mediante capina manual.

A adubação nitrogenada de cobertura foi realizada aos 35 dias após a emergência das plântulas (estádio $\mathrm{V}_{6}$ ), com aplicação de $80 \mathrm{~kg} \mathrm{ha}^{-1}$ de N (ureia) para todos os tratamentos. A colheita foi realizada manualmente no estádio 10 (grãos com teor de água de 20\%), na área útil da parcela.

Após a colheita, os grãos obtidos na área útil da parcela foram amostrados e secos até atingir massa constante, triturados para determinação da composição mineral, teor proteico e cinzas. Determinaram-se os teores de P, K, $\mathrm{Ca}, \mathrm{Mg}, \mathrm{Zn}, \mathrm{Cu}, \mathrm{Fe}$ e Mn, de acordo com as metodologias descritas por Malavolta et al. (1997). O teor total de $\mathrm{N}$ foi obtido pelo método Kjeldahl (AOAC, 1995), sendo convertido em teor de proteína pelo uso do fator 6,25. De acordo com IAL (1985), determinou-se a porcentagem de cinzas. O acúmulo de nutrientes, proteínas e cinzas foi obtido com base no teor dos grãos e na produtividade de grãos da área útil da parcela, expressos em quantidade por hectare.

Os dados foram submetidos à verificação de homogeneidade de variância, pelo teste de Bartlett, sendo detectada a ocorrência de não homogeneidade de variância para os dados de teor e acúmulo de manganês e zinco, dessa forma os dados foram transformados pela raiz quadrada de $\mathrm{Y}+0,5$. Em seguida, foram submetidos à análise de variância, e as médias comparadas pelo teste de Tukey $(\mathrm{p}<0,05)$.

\section{RESULTADOS E DISCUSSÃO}

Os teores e acúmulo de $\mathrm{N}$ total nos grãos não apresentaram variação significativa em razão dos níveis de adubação e de inoculação (Tabela 2).

Os teores médios situaram-se entre 14,4 e 15,4 $\mathrm{g} \mathrm{kg}^{-1}$, abaixo dos descritos como adequados $\left(17 \mathrm{~g} \mathrm{~kg}^{-1}\right)$ por Raij
(1996). Contudo, valores semelhantes aos obtidos neste trabalho foram também verificados por Duete et al. (2009), que estudaram o acúmulo de $\mathrm{N}$ pelos grãos de milho quando aplicado no solo $120 \mathrm{~kg} \mathrm{ha}^{-1}$ de $\mathrm{N}$ nas formas amoniacal e nítrica do nitrato de amônio comparado à amídica da ureia, marcados com ${ }^{15} \mathrm{~N}$. Os autores verificaram que os teores de $\mathrm{N}$ total nos grãos não apresentaram ampla variação com as diferentes fontes de $\mathrm{N}$ avaliadas, ficando os valores entre $13,7 \mathrm{e} 17,5 \mathrm{~g} \mathrm{~kg}^{-1}$.

Constatou-se diferença significativa nos teores de $\mathrm{P}$ e K dos grãos de milho em função da inoculação, já para o efeito de adubação e a interação entre esses fatores não houve efeito dos tratamentos (Tabela 2). A presença de inoculação aumentou os teores de $\mathrm{P}$ e K, independentemente do nível de adubação estudado. Mesmo com os acréscimos devido à inoculação com $P$. fluorescens, os teores ficaram abaixo dos descritos como adequados por Raij (1996), que é de 4 e $5 \mathrm{~g} \mathrm{~kg}^{-1}$ de grãos para $\mathrm{P}$ e K, respectivamente. Embora os teores de $\mathrm{P}$ e $\mathrm{K}$ tenham sido aumentados pela inoculação, os acúmulos desses nutrientes nos grãos não foram alterados com os diferentes tratamentos. Esses resultados corroboram com Fernandes et al. (2008), que relataram o efeito do inoculante Rizofos ${ }^{\circledR}$ (Pseudomonas fluorescens) e da adubação fosfatada no crescimento e na produtividade de Panicum maximum cv. Mombaça e constataram que o inoculante proporcionou aumento nos teores foliares de $\mathrm{P}$ e a adubação fosfatada aumentou a taxa de alongamento foliar, mas não promoveu incrementos nos teores foliares.

Os diferentes níveis de adubação, a presença e ausência de inoculação e a interação entre esses fatores não exerceram efeitos significativos nos teores e no acúmulo de Ca e Mg (Tabela 2). Crusciol et al. (2003) avaliaram os teores de nutrientes nos grãos do arroz de terras altas, obtidos em dois anos de experimentos de campo com diferentes lâminas de água e níveis de adubação mineral com NPK (300 e $600 \mathrm{~kg} \mathrm{ha}^{-1}$ do formulado 04-30-10), e

Tabela 2. Teores $\left(\mathrm{g} \mathrm{kg}^{-1}\right)$ e acúmulos $\left(\mathrm{kg} \mathrm{ha}^{-1}\right)$ médios de $\mathrm{N}, \mathrm{P}, \mathrm{K}, \mathrm{Ca}$ e $\mathrm{Mg}$ em grãos de milho provenientes de plantas cultivadas sob diferentes níveis de adubação NPK e inoculação das sementes com Pseudomonas fluorescens

\begin{tabular}{|c|c|c|c|c|c|c|c|c|c|c|}
\hline \multirow{3}{*}{$\begin{array}{l}\text { Causas } \\
\text { de variação } \\
\text { Adubação }\left(\mathrm{kg} \mathrm{ha}^{-1}\right)\end{array}$} & \multicolumn{10}{|c|}{ Variáveis } \\
\hline & \multicolumn{2}{|c|}{$\mathbf{N}$} & \multicolumn{2}{|c|}{$\mathbf{P}$} & \multicolumn{2}{|c|}{$\mathbf{K}$} & \multicolumn{2}{|c|}{$\mathbf{C a}$} & \multicolumn{2}{|c|}{ Mg } \\
\hline & Teor $^{\text {ns }}$ & Acúmulons & Teor ${ }^{\text {ns }}$ & Acúmulo ${ }^{\mathrm{ns}}$ & Teor $^{\mathrm{ns}}$ & Acúmulo $^{\text {ns }}$ & Teor ${ }^{\mathrm{ns}}$ & Acúmulo ${ }^{\mathrm{ns}}$ & Teor ${ }^{\mathrm{ns}}$ & Acúmulo ${ }^{\mathrm{ns}}$ \\
\hline 0 & 15,40 & 39,94 & 1,25 & 3,26 & 2,82 & 7,32 & 2,76 & 7,38 & 1,37 & 3,61 \\
\hline 125 & 15,03 & 39,05 & 1,28 & 3,22 & 2,85 & 7,43 & 2,47 & 6,92 & 1,24 & 3,22 \\
\hline 250 & 14,40 & 41,18 & 1,40 & 4,37 & 2,92 & 8,88 & 2,35 & 7,17 & 1,35 & 4,14 \\
\hline Inoculação & Teor $^{\text {ns }}$ & Acúmulons $^{\mathrm{ns}}$ & Teor* & Acúmulo $^{\mathrm{ns}}$ & Teor* & Acúmulo $^{\text {ns }}$ & Teor $^{\mathrm{ns}}$ & Acúmulo ${ }^{\mathrm{ns}}$ & Teor $^{\mathrm{ns}}$ & Acúmulo $^{\text {ns }}$ \\
\hline Sem & 15,11 & 41,50 & $1,17 \mathrm{~b}$ & 3,30 & $2,72 b$ & 7,66 & 2,62 & 7,62 & 1,24 & 3,54 \\
\hline Com & 14,77 & 38,72 & $1,46 \mathrm{a}$ & 3,93 & $3,01 \mathrm{a}$ & 8,09 & 2,44 & 6,7 & 1,41 & 3,77 \\
\hline $\mathrm{CV}(\%)$ & 23,07 & 24,37 & 25,23 & 29,72 & 9,98 & 21,53 & 20,15 & 34,66 & 15,28 & 25,41 \\
\hline
\end{tabular}

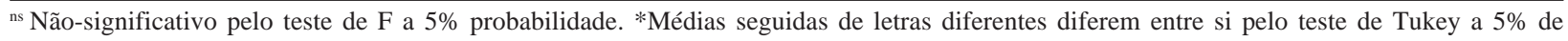
probabilidade.

Rev. Ceres, Viçosa, v. 59, n.5, p. 709-715, set/out, 2012 
constataram que os teores de nutrientes $\mathrm{N}, \mathrm{P}, \mathrm{K}, \mathrm{Ca}, \mathrm{Mg}$, $\mathrm{S}, \mathrm{Fe}, \mathrm{Zn}, \mathrm{Cu}$ e $\mathrm{Mn}$ nos grãos brunidos e a qualidade industrial deles não foram afetados pelo aumento da adubação mineral em solo com teores adequados de nutrientes, assim como também observado neste estudo para a cultura do milho.

Já Ferreira et al. (2001) ao avaliarem os efeitos da adubação com $N\left(0,70,140\right.$ e $\left.210 \mathrm{~kg} \mathrm{ha}^{-1}\right)$, Mo e Zn e suas interações sobre a produção e qualidade de grãos de milho, sob o aspecto protéico e teor de nutrientes nos grãos, observaram efeitos positivos na qualidade dos grãos de milho com o aumento nos teores de proteína e dos nutrientes minerais $\mathrm{P}, \mathrm{K}, \mathrm{Ca}, \mathrm{Mg}, \mathrm{S}, \mathrm{Cu}, \mathrm{Fe}, \mathrm{Mn}$ e $\mathrm{Zn}$, em consequência do aumento na adubação nitrogenada.

Os diferentes níveis de adubação, a presença e ausência de inoculação e a interação entre estes fatores não demonstraram efeitos significativos sobre os teores e acúmulo de Fe, Mn e Zn nos grãos de milho (Tabela 3).

Nakagawa \& Rosolem (2005) avaliaram o efeito de doses de fósforo $\left(0,40\right.$ e $\left.80 \mathrm{~kg} \mathrm{ha}^{-1}\right)$ e potássio $(0,20$ e 40 $\mathrm{kg} \mathrm{ha}^{-1}$ ) juntamente com $50 \mathrm{~kg} \mathrm{ha}^{-1}$ de nitrogênio sobre os teores de nutrientes nas folhas e nos grãos de aveiapreta, e também verificaram que os teores de Fe, Mn e Zn nos grãos não foram influenciados pelas doses de fósforo e potássio aplicados no solo. Já Souza et al. (1998), avaliando o efeito isolado e combinado de adubação com $\mathrm{P}\left(0,50,100,150\right.$ e $200 \mathrm{~kg} \mathrm{ha}^{-1}$ de $\left._{2} \mathrm{O}_{5}\right)$ e $\mathrm{Zn}(0$, $5,10,15$ e $20 \mathrm{~kg} \mathrm{ha}^{-1} \mathrm{de} \mathrm{Zn}$ ) na cultura do milho, constataram que a adubação fosfatada aumentou significativamente a produção de grãos e os teores de P nas folhas; no entanto, não alterou significativamente as concentrações de Zn. Shafea \& Saffari (2011), avaliaram a adubação com N (120, 260 e $400 \mathrm{~kg} \mathrm{ha}^{-1}$ de ureia) e Zn (0, 15 e $30 \mathrm{Kg} \mathrm{ha}^{-1}$ de $\mathrm{ZnSO}_{4}$ ) na cultura de milho de primeira safra, e verificaram que houve aumentou os teores de Zn e Fe nos grãos de milho.
Constatou-se diferença significativa no teor de $\mathrm{Cu}$ nos grãos de milho em razão da adubação, contudo o acúmulo de Cu não foi influenciado pelos tratamentos (Tabela 3). O nível zero de adubação resultou em maior teor de $\mathrm{Cu}$ no grão, diferindo dos resultados obtidos por Crusciol et al. (2003), que não verificaram influência da adubação NPK sobre o teor de $\mathrm{Cu}$.

Os diferentes níveis de adubação, a presença e ausência de inoculação e a interação entre esses fatores não se mostraram efetivos em modificar a porcentagem de proteína e cinzas nos grãos de milho, como pode ser observado na Tabela 4. Contrariando os resultados deste estudo, Ferreira et al. (2001) e Almodares et al. (2009) encontraram efeitos positivos na qualidade dos grãos de milho com o aumento nos teores de proteína em consequência do aumento na adubação nitrogenada. E ainda Kolchinski \& Schuch (2004), avaliando doses de adubação nitrogenada sobre atributos qualitativos dos grãos de aveia branca, constaram que o incremento nas doses de adubação nitrogenada eleva a concentração e a produção de proteína nas cariopses.

As mais baixas porcentagens de cinzas ocorreram na ausência de adubação, possivelmente devido à menor disponibilidade de minerais no solo. Embora não tenha diferido em razão da adubação, o teor de cinzas apresenta-se crescente em função do aumento nos níveis de adubação, pois, segundo Ferreira et al. (2001), a disponibilidade de minerais no solo influencia a composição mineral foliar e esta, por sua vez, a composição mineral dos grãos de milho.

As condições climáticas durante o ciclo da cultura não foram ideais para o desenvolvimento das plantas (Figura 1), ocorrendo estiagem no final de março até o início de maio e geadas no início de junho. De acordo com Cardoso et al. (2004) os elementos climáticos apresentam grande variabilidade espacial e temporal devido à ocorrência de períodos prolongados de escassez de chuvas e temperatu-

Tabela 3. Teores $\left(\mathrm{mg} \mathrm{kg}^{-1}\right)$ e acúmulos $\left(\mathrm{g} \mathrm{ha}^{-1}\right)$ médios de $\mathrm{Fe}, \mathrm{Mn}, \mathrm{Cu}$ e $\mathrm{Zn}$ em grãos de milho provenientes de plantas cultivadas sob diferentes níveis de adubação NPK e inoculação das sementes com Pseudomonas fluorescens

\begin{tabular}{|c|c|c|c|c|c|c|c|c|}
\hline \multirow{3}{*}{$\begin{array}{l}\text { Causas } \\
\text { de variação }\end{array}$} & \multicolumn{8}{|c|}{ Variáveis } \\
\hline & \multicolumn{2}{|c|}{$\mathrm{Fe}$} & \multicolumn{2}{|c|}{$\mathbf{M n}^{1}$} & \multicolumn{2}{|c|}{$\mathrm{Cu}$} & \multicolumn{2}{|c|}{$\mathbf{Z n}^{1}$} \\
\hline & Teor $^{\mathrm{ns}}$ & Acúmulo $^{\text {ns }}$ & Teor $^{\text {ns }}$ & Acúmulo $^{\text {ns }}$ & Teor* & Acúmulo $^{\text {ns }}$ & Teor ${ }^{\text {ns }}$ & Acúmulons \\
\hline$\overline{0}$ & 75,95 & 183,88 & 1,48 & 5,36 & $5,22 \mathrm{a}$ & 14,11 & 9,02 & 23,4 \\
\hline 125 & 64,45 & 116,95 & 1,33 & 4,36 & $4,85 \mathrm{ab}$ & 13,00 & 12,12 & 31,6 \\
\hline 250 & 70,75 & 208,83 & 1,26 & 3,84 & $3,47 \mathrm{~b}$ & 10,53 & 11,81 & 36,2 \\
\hline Inoculação & Teor ${ }^{\mathrm{ns}}$ & Acúmulo $^{\text {ns }}$ & Teor ${ }^{\text {ns }}$ & Acúmulo $^{\text {ns }}$ & Teor $^{\text {ns }}$ & Acúmulo $^{\text {ns }}$ & Teor $^{\text {ns }}$ & Acúmulo $^{\mathrm{ns}}$ \\
\hline Sem & 73,12 & $\overline{193,94}$ & 1,50 & 5,21 & 4,70 & 13,52 & $11, \overline{38}$ & 34,9 \\
\hline Com & 67,66 & 175,84 & 1,21 & 3,84 & 4,32 & 11,55 & 10,60 & 25,90 \\
\hline$\overline{\mathrm{CV}(\%)}$ & 30,52 & 27,76 & 26,60 & 30,23 & 25,50 & 27,58 & 27,20 & 31,80 \\
\hline
\end{tabular}


ras baixas no período usual de cultivo do milho "safrinha" no Paraná. A produção por área pode ser comprometida se a deficiência hídrica coincidir com o período do florescimento, fase que determina a quantidade de óvulos a serem fecundados e, por consequência, a produção de grãos.

Nas três semanas que antecederam o florescimento masculino não houve registros de precipitação pluviométrica (Figura 1) o que certamente contribuiu para redução de produtividade, que apresentou média de $2.740 \mathrm{~kg} \mathrm{ha}^{-1}$, sendo inferior a média para o estado do Paraná que situa -se entre 3.000 a $4.000 \mathrm{~kg} \mathrm{ha}^{-1}$ para o milho de segunda safra (CONAB, 2009). A remobilização dos nutrientes móveis para os grãos de milho também pode ter sido afetada pela ausência de precipitação, pois para absorção e translocação de minerais pela planta é necessário umidade no solo. Assim, as condições climáticas desfavoráveis podem ter afetado o teor de nutrientes nos grãos, bem como o de proteína e cinzas.

As rizobactérias exercem efeitos benéficos ao promover o crescimento vegetal, o que ocorre devido ao aumento da disponibilidade de nutrientes para as plantas, pela solubilização de fosfato inorgânico (Zahir et $a l ., 2004)$ e pelo maior crescimento de raiz, favorecendo a absorção de nutrientes e o teor e acúmulo de nutrientes nos grãos (Mantelin \& Touraine, 2004). Além de comprometer o desenvolvimento e potencial produtivo da cultura do milho, possivelmente as condições desfavoráveis de clima afetaram também a sobrevivência, a estabilidade, a multiplicação e a associação das rizobactérias com a cultura. Portanto, é necessário dar continuidade aos estudos com Pseudomonas fluorescens na cultura do milho em condições climáticas favoráveis, em que a adubação e a inoculação com $P$. fluorescens possam expressar seus possíveis efeitos sobre o desenvolvimento e nutrição da planta e, consequentemente, sobre a qualidade nutricional do grão.

Tabela 4. Teores $\left(\mathrm{g} \mathrm{kg}^{-1}\right)$ e acúmulos $\left(\mathrm{kg} \mathrm{ha}^{-1}\right)$ de proteína e cinzas (\%) em grãos de milho provenientes de plantas cultivadas sob diferentes níveis de adubação NPK e inoculação das sementes com Pseudomonas fluorescens

\begin{tabular}{|c|c|c|c|c|}
\hline \multirow{3}{*}{$\begin{array}{l}\text { Causas } \\
\text { de variação } \\
\text { Adubação }(\%)\end{array}$} & \multicolumn{4}{|c|}{ Variáveis analisadas } \\
\hline & \multicolumn{2}{|c|}{ proteína } & \multicolumn{2}{|c|}{ cinzas } \\
\hline & Teor ${ }^{\mathrm{ns}}$ & Acúmulo ${ }^{\text {ns }}$ & Teor ${ }^{\mathrm{ns}}$ & Acúmulo ${ }^{\mathrm{n}}$ \\
\hline 0 & 117,4 & 310,0 & 15,7 & 40,75 \\
\hline 125 & 113,8 & 293,5 & 16,0 & 41,40 \\
\hline 250 & 115,8 & 333,5 & 16,5 & 47,20 \\
\hline Inoculação & Teor $^{\mathrm{ns}}$ & Acúmulo ${ }^{\mathrm{ns}}$ & Teor ${ }^{\mathrm{ns}}$ & Acúmulo ${ }^{\mathrm{n}}$ \\
\hline Sem & 116,1 & 316,50 & 16,2 & 44,1 \\
\hline Com & 115,3 & 302,05 & 15,9 & 42,1 \\
\hline$\overline{C V}(\%)$ & 6,92 & 17,88 & 11,94 & 16,08 \\
\hline
\end{tabular}

Rev. Ceres, Viçosa, v. 59, n.5, p. 709-715, set/out, 2012

\section{CONCLUSÃO}

A aplicação de Pseudomonas fluorescens via inoculação incrementou os teores de $\mathrm{P}$ e $\mathrm{K}$ dos grãos de milho, independentemente dos níveis de adubação.

Os teores dos nutrientes, de proteína e de cinzas dos grãos de milho não foram influenciados pelos níveis de adubação mineral, com exceção do $\mathrm{Cu}$, que aumentou com a elevação dos níveis de adubação.

\section{REFERÊNCIAS}

Afzal A \& Bano A (2008) Rhizobium and phosphate solubilizing bactéria improve the yild and phosphorus uptake in wheat (Triticum aestivum). International Journal of Agriculture and Biology, 10:85-88.

Almodares A, Jafarinia M \& Hadi MR (2009) The effects of nitrogen fertilizer on chemical compositions in corn and sweet sorghum. American-Eurasian Journal Agricultural \& Environmental Sciences, 6:441-446.

Andreotti M, Souza ECA, Crusciol CAC, Rodrigues JD \& Büll LT (2000) Produção de matéria seca e absorção de nutrientes pelo milho em razão da saturação por bases e da adubação potássica. Pesquisa Agropecuária Brasileira, 35:2437-2446.

Association of Official Analytical Chemists - AOAC (1995) Official methods of analysis. $16^{\mathrm{a}}$ ed. Washington, D.C, AOAC International, $1094 \mathrm{p}$.

Bueno LG, Chaves LJ, Oliveira JP, Brasil EM, Reis AJS, Assunção A, Pereira AF \& Ramos MR (2009) Controle genético do teor protéico nos grãos e de caracteres agronômicos em milho cultivado com diferentes níveis de adubação nitrogenada. Pesquisa Agropecuária Brasileira, 44:590-598.

Cardoso CO, Faria RT \& Folegatti MV (2004) Simulação do rendimento e riscos climáticos para o milho safrinha em Londrina - PR, utilizando o modelo CERES-Maize. Engenharia Agrícola, 24:291-300.

Carmo CAFS, Meneguelli NA, Macedo JR, Capeche CL, Melo AS \& Silva EF (2003) Acúmulo de nutrientes em milho cultivado em Nitossolo degradado sob diferentes fontes de adubação. Magistra, 15:01-14.

Coelho AM, Waquil JM, Karam D, Casela CR \& Ribas PM (2002) Seja o doutor do seu sorgo. Piracicaba, Potafos. p.1-24. (Comunicado Técnico, 100).

Companhia Nacional de Abastecimento - CONAB (2009) Acompanhamento da safra brasileira de grãos. $12^{\mathrm{a}}$ ed. Brasília, CONAB, $39 \mathrm{p}$.

Crusciol CAC, Arf O, Soratto RP \& Machado JR (2003) Qualidade industrial e teores de nutrientes dos grãos do arroz de terras altas sob diferentes lâminas de água e níveis de adubação mineral. Acta Scientiarum Agronomy, 25:409-415.

Duete RRC, Muraoka T, Silva EC, Ambrosano EJ \& Trivelin PCO (2009) Acúmulo de nitrogênio $\left({ }^{15} \mathrm{~N}\right)$ pelos grãos de milho em função da fonte nitrogenada em Latossolo vermelho. Bragantia, 68:463-472.

Empresa Brasileira de Pesquisa Agropecuária - Embrapa (1999) Centro Nacional de Pesquisa de Solos. Sistema brasileiro de classificação de solos. Rio de Janeiro, Embrapa Solos. 412p. 
Empresa Brasileira de Pesquisa Agropecuária - Embrapa (2009) Nutrição e Adubação do Milho. Disponível em: <http:// www.cnpms.embrapa.br/publicacoes/milho/feraduba.htm>. Acessado em: 15 de fevereiro de 2009.

Fancelli AL \& Dourado Neto D (2004) Produção de milho. $2^{\mathrm{a}}$ ed. Piracicaba, Livro Ceres. 360p.

Fernandes JC, Andreotti M, Pariz CM, Cavasano FA, Ulian NA \& Cavallini MC (2008) Crescimento e produtividade de forragem do Panicum maximum cv. Mombaça em função da inoculação com Rizofós (Pseudomonas fluorescens) e adubação fosfatada. In: $28^{\circ}$ Reunião Brasileira de Fertilidade do Solo e Nutrição de Plantas, Londrina. Anais, Fertibio. p.1-4.

Ferreira ACB, Araújo GAA, Pereira PRG \& Cardoso AA (2001) Características agronômicas e nutricionais do milho adubado com nitrogênio, molibdênio e zinco. Scientia Agricola, 58:131138.

Glick BR, Todorovic B, Czarny J, Cheng Z, Duan J \& McConkey B (2007) Promotion of plant growth by bacterial ACC deaminase. Critical Reviews in Plant Sciences. 26:227-242.

Normas Analíticas do Instituto Adolfo Lutz - IAL (1985) Métodos Químicos e físicos para Análise de Alimentos. $3^{\text {a }}$ ed. São Paulo, Instituto Adolfo Lutz. 533p.

Instituto Agronômico do Paraná - IAPAR (2008) Monitoramento Agroclimático do Paraná. Disponível em: <http:// 200.201.27.14/Site/Sma/Index.html >. Acessado em: 20 de abril de 2008 .

Instituto Agronômico do Paraná - IAPAR (2009) Zoneamento climático. Disponível em: <http://www.iapar.br/modules/ conteudo/conteudo.php?conteudo=1089>. Acessado em: 30 de janeiro de 2009.

Kolchinski EM \& Schuch LOB (2004) Relações entre a adubação nitrogenada e a qualidade de grãos e de sementes em aveia branca. Ciência Rural, 34:379-383.

Malavolta E, Vitti GC \& Oliveira AS (1997) Avaliação do estado nutricional das plantas: princípios e aplicações. Piracicaba, Potafos. 319 p.

Mantelin S \& Touraine B (2004) Plant growth-promoting bacteria and nitrate availability: impacts on root development and nitrate uptake. Journal Experimental Botany, 55:27-34.

Marsaro Júnior AL, Lazzari SMN, Souza JL, Lazzari FA \& Cândido LMB (2007) Influência de diferentes sistemas de adubação na composição nutricional do milho Zea mays L. (Poaceae) e seus efeitos no ataque de Sitophilus zeamais Motschulsky (Coleóptera: Curculionidae) no produto armazenado. Semina: Ciências Agrárias, 28:51-64.

Mittelmann A, Miranda Filho JB, Lima GJMM, Hara-Klein C, Silva RM \& Tanaka RT (2006) análise dialélica do teor de óleo em milho. Revista Brasileira de Agrociência, 12:139-143.

Nakagawa J \& Rosolem CA (2005) Teores de nutrientes da folha e nos grãos de aveia-preta em função da adubação com fósforo e potássio. Bragantia, 64:441-445.
Oliveira JPO, Chavez LJ, Duarte JB, Brasil EM, Ferreira Junior LT \& Ribeiro KO (2004) Teor de proteína no grão em populações de milho de alta qualidade protéica e seus cruzamentos. Pesquisa Agropecuária Tropical, 34: 45-51.

Pan B, Bai YM, Leibovitch S \& Smith DL (1999) Plant-growth promoting rhizobacteria and kinetin as ways to promote corn growth and yield in a short-growing-season area. European Journal of Agronomy, 11:179-186.

Pionner Sementes. Híbridos de milho: 30F35 (2009) Disponível em: <http://www.pioneersementes.com.br/ ProdutosDetalheMilho asp $\mathrm{x}$ ? id $=65 \& \mathrm{gclid}=\mathrm{CNK} 2 \mathrm{wLums} 54$ CFYce7godKW2yag>. Acessado em: 30 de novembro de 2009.

Raij BV (1996) Recomendações de adubação e calagem para o Estado de São Paulo. $2^{\mathrm{a}}$ ed. Campinas, Instituto Agronômico. 285p. (Boletim técnico, 100).

Raij BV \& Quaggio AJ (1983) Métodos de análise de solo para fins de fertilidade. Campinas, Instituto Agronômico. 31p.

Ritchie SW, Hanway JJ \& Benson GO (1986) How a Corn Plant Develops. Ames, Iowa State University of Science and Technology. 21p. (Special Report, 48)

Shafea L \& Saffari M (2011) Effects of zinc $\left(\mathrm{ZnSO}_{4}\right)$ and nitrogen on chemical composition of maize grain. International Journal of AgriScience, 1:323-328.

Sheng XF \& He LY (2006) Solubilization of potassium-bearing minerals by a wildtype strain of Bacillus edaphicus and its mutants and increased potassium uptake by wheat. Canadian Journal of Microbiology, 52:66-72.

Sobrinho WN, Santos RV, Menezes Júnior JC \& Souto JS (2009) Acúmulo de nutrientes nas plantas de milheto em função da adubação orgânica e mineral. Caatinga, 22:107-110.

Sottero NA, Freitas SS, Melo AMT \& Trani PE (2006) Rizobactérias e alface: colonização rizosférica, promoção de crescimento e controle biológico. Revista Brasileira de Ciência do Solo, 30:225-234.

Souza ECA, Coutinho ELM, Natale W \& Barbosa JC (1998) Respostas do milho à adubação com fósforo e zinco. Pesquisa Agropecuária Brasileira, 33:1031-1036.

Vasconcelos CA, Viana MCM \& Ferreira JJ (1998) Acúmulo de matéria seca e de nutrientes em milho cultivado no período inverno-primavera. Pesquisa Agropecuária Brasileira, 33:18351845 .

Zaidi A \& Khan MS (2006) Co-inoculation effects of phosphate solubilizing microorganisms and glomus fasciculatum on green gram-bradyrhizobium symbiosis. Turkish Journal of Agriculture and Forestry, 30:223-230.

Zahir A, Arshad ZM \& Frankenberger WF (2004) Plant growth promoting rhizobacteria: applications and perspectives in agriculture. Advances in Agronomy, 81:97-168.

Zhang F, Mackenzie AF \& Smith DL (1994) Nitrogen fertilizer and protein, lipid, and non-structural carbohydrate concentrations during the course of maize kernel filling. Journal of Agronomy \& Crop Science, 172:171-181. 